\title{
O TDAH NO CAMPO DA ASSISTÊNCIA SOCIAL: POSSIBILIDADES PARA UMA CLÍNICA AMPLIADA
}

\author{
ADHD In The Field Of Social Welfare: Possibilities For An Extended Clinic \\ TDAH En El Campo De La Asistencia Social: Posibilidades Para Una Clinica Extendida
}

Luiz Gustavo Santos Tessaro Ana Maria Veiga Lima

\begin{abstract}
Resumo: Este artigo teórico teve como objetivos constituir uma revisão da literatura gestáltica acerca do TDAH até então produzida no Brasil e discutir possibilidades práticas de intervenção fundamentadas na Gestalt-terapia. Tais propostas tiveram como cenário de elaboração o contexto de um serviço de assistência social que acolhe crianças e adolescentes, com ou sem o diagnóstico. Assim, compreendeu-se a necessidade de uma articulação com a ideia de uma clínica ampliada, sustentada no conceito de campo de Kurt Lewin. Também foram consideradas as contribuições de Luciana Aguiar e de Violet Oaklander, importantes autoras da psicoterapia gestáltica com crianças, no Brasil e no mundo, respectivamente. Dentre os resultados, encontrou-se a necessidade de intervenções em âmbito institucional (como trabalhar introjetos da instituição e ofertar maior supervisão e acompanhamento a essas crianças) e individual (realização de atividades sensório motoras e voltadas para o desenvolvimento do protagonismo por meio da possibilidade de escolher).
\end{abstract}

Palavras-chave: Terapia Gestalt; Psicologia Clínica; Psicologia Social.

\begin{abstract}
This theoretical article aimed to constitute a review of the gestalt literature about Attention Deficit Hyperactivity Disorder (ADHD) produced in Brazil and to discuss practical possibilities of intervention based on Gestalt therapy. These proposals were designed in the context of a social welfare service that welcomes children and adolescents, with or without the diagnosis of ADHD. Thus, was necessary to articulate with the concept of extended clinic, supported by the field concept of Kurt Lewin. Was considered the contributions of Luciana Aguiar and Violet Oaklander, two important authors of gestalt psychotherapy with children, in Brasil and in the world, respectively. Among the results, there was the need for interventions at the institutional level (such as working within the institution's introjects and offering greater supervision and monitoring to these children) and individual (performing motor sensory activities aimed at the development of the protagonism through the possibility of to choose).
\end{abstract}

Keywords: Gestalt Therapy; Clinical Psychology; Social Psychology.

Resumen: Este artículo teórico tuvo como objetivos constituir una revisión de la literatura gestáltica acerca del TDAH hasta entonces producida en Brasil y discutir posibilidades prácticas de intervención fundamentadas en la Gestalt-terapia. Tales propuestas tuvieron como escenario de elaboración el contexto de un servicio de asistencia social que acoge a niños y adolescentes, con o sin el diagnóstico. Así, se comprendió la necesidad de una articulación con la idea de una clínica ampliada, sustentada en el concepto de campo de Kurt Lewin. También se consideraron las contribuciones de Luciana Aguiar y de Violet Oaklander, importantes autoras de la psicoterapia gestáltica con niños, en Brasil y en el mundo, respectivamente. Entre los resultados, hubo la necesidad de intervenciones a nivel institucional (como trabajar dentro de los introyectos de la institución y ofrecer una mayor supervisión y monitoreo a estos niños) e individuales (realizar actividades sensoriales motoras dirigidas al desarrollo del protagonismo a través de la posibilidad de elegir)

Palabras clave: Terapia Gestalt; Psicología Clínica; Psicología Social.

\section{Introdução}

O Transtorno de Déficit de Atenção/Hiperatividade (TDAH) é um diagnóstico frequente na infância. Pesquisas que ampararam a organização da quinta edição do Manual Diagnóstico e Estatístico dos Transtornos Mentais (DSM-5) mostram uma prevalência do diagnóstico da ordem de 5\% nas crianças (American Psychiatric Association, 2014). Revisões sistemáticas apontaram médias de prevalência da ordem de 8,3\% (Thiengo, Cavalcante \& Lovisi, 2014) e 11,26\% (Hora, Silva, Ramos, Pontes \& Nobre, 2015).

Nas últimas três décadas, a utilização do Me- tilfenidato aumentou significativamente nos países ocidentais, à esteira do crescimento do número de casos diagnosticados (Kamers, 2016). A despeito de realmente tratar-se de um conjunto de sinais e sintomas importantes e que aparecem em um número grande de crianças, interrompendo seu desenvolvimento e contato saudável com o meio, discute-se a possibilidade de que a infância esteja sendo submetida a critérios de "normalidade" discutíveis, com exigências incompatíveis com o grau de desenvolvimento e maturidade individuais (Schwartzman, 2000) e consequente medicalização excessiva.

Nesse sentido, é interessante buscar sempre 
fazer uma diferenciação entre o que é realmente disfuncional e o que é uma exigência desproporcional para uma criança, que pode ser ainda incapaz de atendê-la plenamente por razões desenvolvimentais. É tarefa do psicólogo entender a demanda que chega a ele, o que passa pela realização de um diagnóstico que compreende o campo como um todo (Aguiar, 2005), não apenas o indivíduo e os sintomas apresentados. Por se tratar de uma demanda não restrita aos consultórios particulares - visto que as crianças podem frequentar os mais diversos espaços, como a escola e os serviços de assistência social - a psicologia como um todo e a Gestalt-terapia, em particular, acabam convocadas a uma aplicação da ordem da clínica ampliada.

O levantamento dos termos "TDAH" e "Gestalt-terapia” no portal de pesquisa BVS Saúde Brasil, entretanto, demonstra uma escassez de produções sobre a temática do TDAH na perspectiva da Gestalt-terapia no país, tendo em vista a existência de apenas 4 artigos (Antony \& Ribeiro, 2004; 2005; 2008; Guisso \& Fabro, 2016). É preciso revisitar e ampliar o entendimento teórico do TDAH, sobretudo do fundo que envolve e sustenta esse fenômeno na contemporaneidade, a fim de que, se possível, se evite a medicalização precoce, estigmas e exclusão.

\section{Método}

Este artigo é uma adaptação de uma monografia teórica, apresentada como requisito para conclusão de curso de especialização em Gestalt-terapia. Objetivou, em um primeiro momento, constituir uma revisão da literatura gestáltica acerca do TDAH até então produzida. Em um segundo momento, procurou-se desenvolver possibilidades práticas de intervenção na perspectiva de uma clínica ampliada, sustentada em importantes autoras da psicoterapia com crianças, a saber, Violet Oaklander e Luciana Aguiar.

Para alcançar o primeiro objetivo, realizou-se uma revisão de literatura (Creswell, 2010) com a finalidade de levantar as obras produzidas sobre o tema do TDAH no campo da Gestalt-terapia. Essa revisão iniciou-se com uma pesquisa bibliográfica, seguida de organização do material e escrita. Para tanto, utilizou-se o portal de pesquisa Biblioteca Virtual em Saúde (BVS) Brasil. Os descritores cruzados foram "Transtorno do Déficit de Atenção com Hiperatividade" e "Terapia Gestalt" (termos sugeridos no tesauro da BVS). Foram pesquisados todos os artigos publicados até 2017. Encontrou-se 4 artigos, dos quais um foi descartado após leitura do resumo por não tratar do tópico desta pesquisa, apesar de apresentar os descritores, restando, assim, 3 artigos (Antony \& Ribeiro, 2004, 2005, 2008). A fim de ampliar o número de trabalhos, utilizou-se a ferramenta de busca Google Acadêmico. Nela foram utilizados os mesmos descritores e, subsequentemente, os descritores "TDAH" e "Gestalt-terapia" visto que os anteriores não retornaram novos estudos. Após a leitura dos títulos e resumos, mais dois estudos foram selecionados pois relacionavam os descritores. Contudo, um deles não foi utilizado visto que o periódico não constava na Plataforma Sucupira. Portanto, dessa segunda busca, permaneceu mais 1 estudo (Guisso \& Fabro, 2016). Discutiu-se, subsequentemente, o conteúdo desses artigos.

Para articular as possibilidades práticas, representadas pelo segundo objetivo, foi estabelecido como cenário para discussão o trabalho desenvolvido pelo autor em um espaço público pertencente à política de assistência social: o Serviço de Convivência e Fortalecimento de Vínculos (SCFV) ${ }^{1}$ de 6 a 14 anos. Trata-se de um serviço complementar ao trabalho realizado com famílias na assistência social, oferecido de acordo com a Política Nacional de Assistência Social (PNAS). Esse serviço caracteriza-se por ter um caráter preventivo e proativo, além de visar, por meio da afirmação de direitos e desenvolvimento de potencialidades, a emancipação dos usuários e superação de vulnerabilidades sociais (Ministério do Desenvolvimento Social e Combate à Fome [MDS], 2016). Funciona no contra turno da escola, com atividades socioeducativas, lúdicas e esportivas. Este artigo não conta com relatos particulares de situações de crianças com diagnóstico de TDAH. Porém, elege o SCFV como campo de inserção desses sujeitos e, portanto, lugar propício para possíveis intervenções da Gestalt-terapia. Tais intervenções, dadas as características do serviço, são da ordem da clínica ampliada.

A clínica ampliada é aqui compreendida como uma prática que se dá para além das paredes dos consultórios a qual, sem descartar a compreensão que a psicologia possui sobre o indivíduo, lança-se a uma observação e intervenção sobre o todo no qual ele se insere. Inclui em sua compreensão as relações, em uma lógica muito coerente com a estrutura teórica da Gestalt-terapia. Trata-se de um modelo diferente de atuação (Brito, 2015).

\section{TDAH Como Figura: Histórico e Cri- térios Diagnósticos Atuais}

O pediatra inglês George Still é citado como o autor que, em 1902, teria dado as bases para a construção futura do diagnóstico do TDAH, embora sem nomeá-lo desta forma (Caliman, 2010; Malloy-Diniz, Capellini, Malloy-Diniz \& Leite, 2007). Ele acreditava que existia uma patologia neurofisiológica, ainda desconhecida, a qual acometia crianças e que prejudicava seu sistema inibitório, causando uma deficiência em sua conduta moral (Caliman, 2010). Para Still, a desatenção e a hiperatividade

1 Serviço de Convivência e Fortalecimento de Vínculos (SCFV) trata-se de um serviço de proteção social básica do Sistema Único de Assistência Social. Oferta atividades diversas, tais como artísticas, culturais, esportivas no turno oposto à escola, objetivando o fortalecimento dos vínculos comunitários e o desenvolvimento das capacidades dos usuários (Secretaria Especial do Desenvolvimento Social, 2015). O SCFV que motivou estas reflexões trabalha com crianças e adolescentes de 6 a 14 anos. 
não eram sintomas centrais (a primeira era relacionada a uma falta de controle moral, de "vontade", por parte da criança em manter a atenção). Ele compreendia como centrais a fúria emotiva, a crueldade e a malícia, a inveja, a ausência de lei, a desonestidade, a promiscuidade e a destrutividade, a ausência de modéstia, a vergonha, a imoralidade sexual e o vício (Caliman, 2010).

Posteriormente, por volta do ano de 1918/1919, uma epidemia de encefalite ocorreu nos Estados Unidos e representou um avanço na linha do tempo do diagnóstico em questão. Crianças acometidas pela referida infecção demonstraram, como sequela, problemas de atenção, de regulação da atividade e da impulsividade, deficiências cognitivas, dificuldades de relacionamento interpessoal, comportamento desafiador opositor e delinquência (Pereira, 2009). A chamada "Desordem Pós-Encefálica", assim nomeada tardiamente, representou um marco, porque permitiu que se associasse uma lesão cerebral a uma patologia comportamental, inaugurando uma possível relação causa e efeito, bem como incluiu sintomas de déficit de atenção (Pereira, 2009).

A denominação "Lesão Cerebral Mínima" entrou nesse quadro histórico evolutivo por volta de 1947, através dos pesquisadores Strauss e Lehtinen, e somava, ao leque de sintomas de inadequação social de crianças, hiperatividade e distraibilidade (Antony \& Ribeiro, 2004). A hipótese de lesão cerebral foi abandonada por falta de evidências neurológicas e a nomenclatura usada foi substituída por "Disfunção Cerebral Mínima" (Antony \& Ribeiro, 2004).

A partir da década de 60, com a evolução dos manuais diagnósticos de transtornos mentais, novas nomenclaturas foram surgindo, bem como critérios diagnósticos. O DSM-II, em 1968, trouxe a classificação de "Reação Hipercinética da Infância" (Malloy-Diniz et al., 2007), sendo substituída em 1980 por "Síndrome de Déficit de Atenção com ou sem Hiperatividade” e, em 1987, já na sua terceira edição, renomeada para "Distúrbio de Déficit de Atenção por Hiperatividade” (Antony \& Ribeiro, 2004). As últimas duas versões do DSM trazem a mesma nomenclatura para a classificação nosológica em questão, "Transtorno de Déficit de Atenção/Hiperatividade”. Entretanto, o DSM-IV-TR a situa como um “Transtorno Geralmente Diagnosticado pela Primeira Vez na Infância ou na Adolescência” (American Psychiatric Association, 2008) e o DSM-5 como “Transtorno do Neurodesenvolvimento" (American Psychiatric Association, 2014). Na atual versão CID (CID-10) encontramos correspondência na denominação "Transtornos Hipercinéticos" (Organização Mundial da Saúde, 2011).

O que foi descrito acima é a "história oficial e dominante” do TDAH (Caliman, 2010). Essa versão sofreu e ainda sofre duras críticas no meio acadêmico devido às incertezas etiológicas (Antony \& Ri- beiro, 2005; DuPaul \& Stoner, 2007; Schwartzman, 2000), às controvérsias clínicas, terapêuticas e epidemiológicas e à exclusão de uma análise social que estaria envolvida na gênese do fenômeno (Caliman, 2010). Trata-se de uma história de origem biomédica - do campo da neurologia e da psiquiatria infantil - proveniente de pesquisadores que representam "o discurso da legitimidade biológica e cerebral do transtorno” (Caliman, 2010, p. 49).

A crítica anteriormente exposta não significa, contudo, negar que haja um fenômeno no campo da infância que traz sofrimento à criança, seja pelo acolhimento falho de alguns espaços e pelos modos adultos disfuncionais de lidar com a questão, seja pela própria experiência que a sintomatologia apresentada proporciona. A Gestalt-terapia contribui com essa reflexão a partir da compreensão do sintoma enquanto ajustamento criativo, que aparece como uma tentativa de neutralização da angústia e aponta para gestalten abertas, necessidades insatisfeitas (Antony, 2009). Mais do que enquadrar uma criança em uma categoria diagnóstica, atribuindo a ela o estigma atrelado, é necessária uma apreciação da totalidade que sustenta a figura ${ }^{2}$ sintomatológica em questão.

Uma concepção puramente fisiológica do transtorno, desconectada do todo envolvido, em detrimento de uma só parte, constituiria um erro epistemológico para com a abordagem gestáltica. Além disso, pode simplificar sobremaneira um problema complexo e, assim, legitimar um processo de hipermedicalização da infância, patologização da vida, culpabilização e estigmatização da pessoa.

Também é importante fazer uma breve observação sobre o que os manuais diagnósticos mais atuais apregoam. A familiaridade com esse tópico é útil para o diálogo interdisciplinar. A quinta versão do DSM define o TDAH como "um padrão persistente de desatenção e/ou hiperatividade-impulsividade" (American Psychiatric Association, 2014, p. 61). Acrescenta que este padrão interfere no desenvolvimento e funcionamento esperados para um indivíduo. Alguns fatores relacionados à desatenção são: dificuldade de organizar e finalizar tarefas, perdas, esquecimentos e erros por distração. Já os fatores relacionados à hiperatividade e impulsividade envolvem a dificuldade em manter-se sentado, loquacidade, interrupções, entre outros (American Psychiatric Association, 2014).

A CID-10 parece ser mais vaga na descrição dos critérios diagnósticos para o que chama de "Transtornos Hipercinéticos”. Afirma que são características desse grupo de transtornos: o começo precoce, a presença de desatenção, de hiperatividade, de conduta

2 Figura e fundo são dois conceitos inseparáveis, oriundos da Psicologia da Gestalt em suas contribuições sobre a percepção. A figura pode ser compreendida como uma necessidade que emerge e mobiliza o indivíduo para a ação. O fundo dá sustentação à emergência de figuras e é composto, basicamente, pelas vivências anteriores, pelas situações inacabadas e pelo fluxo da experiência presente (Polster \& Polster, 2001). 
invasiva e de persistência desses sintomas ao longo do tempo. O comprometimento da atenção e a presença de hiperatividade, contudo, são fatores indispensáveis para o diagnóstico e devem estar presentes em variados contextos da vida da pessoa (Organização Mundial da Saúde, 2011). O comprometimento da atenção se apresenta de formas semelhantes às descritas no DSM-5, no entanto a descrição é menos exaustiva. O manual traz que as crianças tendem a mudar de atividades com frequência, demonstrando rápida perda de interesse e dificuldade de manter a atenção. No que tange à hiperatividade, esta se expressa na excessiva inquietação, loquacidade e agitação motora em comparação com o contexto, com o que é esperado. Outras características secundárias e não necessárias para o diagnóstico são a desinibição, a imprudência em situações de perigo, e zombarias das regras sociais (Organização Mundial da Saúde, 2011).

Uma crítica importante, com base no que traz a CID-10, é que esta considera que, antes da idade escolar, em relação à hiperatividade, existe uma "ampla variação normal" (Organização Mundial da Saúde, 2011, p. 258). No período escolar, contudo, dissolve-se esse espectro de normalidade frente às demandas acadêmicas. Não há uma problematização de possíveis efeitos do contexto social no surgimento, na manutenção ou no aumento de sintomas. A variação normal parece ser substituída por uma expectativa de homogeneidade.

O Gestalt-terapeuta necessita de norteadores diagnósticos, todavia não pode, sob risco de romper com a antropologia que fundamenta sua prática, colocar-se em um papel de quem deve apenas amenizar sintomas para atender a necessidades institucionais ou familiares. O sintoma é um estilo de ser-no-mundo, um comunicador de informações, cujo sentido só pode ser compreendido na inserção do sujeito no campo (Galli, 2009).

\section{As Contribuições da Gestalt-Terapia Brasileira: Uma Revisão da Literatura}

A Gestalt-terapia tem na Teoria Organísmica e na Teoria Holística, alicerces significativos. A primeira, de autoria de Kurt Goldstein, postula que o organismo é um todo integrado, de forma que uma mudança em uma parte, tal como uma Gestalt, afeta o funcionamento do todo (Ribeiro, 2012). Já o Holismo de Jam Fleming Smuts amplia o conceito anterior, na medida em que considera o universo como um grande todo, composto de subtodos, onde tudo está interligado (Ribeiro, 2011). Consequentemente, assim como na compreensão de Goldstein, os subtodos afetam o todo maior o qual compõem.

Nesse sentido, em coerência com essas que são duas fundamentais "teorias de base" (Ribeiro, 2011) da Gestalt-terapia, é necessário olhar para o todo, para o conjunto de discursos e saberes que tentam explicar a etiologia do fenômeno em questão, neste estudo. É necessário fazer esse movimento, não só com intuito crítico - que é interessante pois desacomoda, reconfigura - mas com objetivo de promover integração de saberes, de romper com cisões entre as disciplinas que trabalham com pessoas com TDAH. De acordo com o mais famoso fundador da Gestalt-terapia, esta abordagem "é uma filosofia que tenta estar em harmonia, em acordo com tudo mais, com a medicina, com a ciência, com o universo, com aquilo que é" (Perls, 1977b, p. 33). Essa postura também é coerente com a compreensão atual de que o TDAH é um transtorno de gênese multifatorial (Antony \& Ribeiro, 2004). Assim, fica manifesta a necessidade de um diálogo interdisciplinar, sem o qual torna-se muito difícil intervir eficazmente dada a evidência de que há uma série de fatores envolvidos e em relação e não apenas uma causalidade linear.

No meio biomédico, até o momento, não é conhecida uma "causa única" do TDAH e não existe um exame complementar de neuroimagem que possa confirmar o diagnóstico clínico (Antony \& Ribeiro, 2005; DuPaul \& Stoner, 2007; Malloy-Diniz et al., 2007; Sadock, Sadock \& Ruiz, 2017). Existem, contudo, achados correlacionais entre o TDAH e variações no córtex pré-frontal; nesse mesmo local, neurotransmissores como a dopamina e a norepinefrina estariam menos disponíveis, hipótese essa baseada na ação de medicamentos psicoestimulantes como o Metilfenidato (DuPaul \& Stoner, 2007, Sadock, Sadock \& Ruiz, 2017), psicofármaco amplamente usado no tratamento deste transtorno. Desconhece-se, contudo, as razões para tais anormalidades. Estudos com gêmeos têm apontado para um alto grau de transmissão genética do TDAH, o que se daria devido a diferenças nos genes transportadores (DAT) e receptores (DRD4) de dopamina (Barkley \& Murphy, 2008; DuPaul \& Stoner, 2007, Sadock, Sadock \& Ruiz, 2017).

Além de um olhar específico sobre possíveis causas individuais, também se pode olhar para o meio ao qual tal sujeito se insere. Conforme Antony e Ribeiro (2004) há pesquisas que apontam para características de personalidade dos pais como fatores que poderiam desencadear e interferir no curso do TDAH. Esse diagnóstico na criança poderia ser uma reação a uma situação de permanente angústia e ansiedade. O TDAH também poderia estar associado a contextos familiares pouco afetivos, onde há constante desvalorização da criança, crítica, abuso, maus tratos, negligência, falta de atenção e controle precário dos impulsos (Sadock, Sadock \& Ruiz, 2017). Quanto aos fatores relacionados à alimentação (tais como ingestão de açúcares e colorantes alimentares artificiais), os quais poderiam estar relacionadas a sintomas do TDAH, não há evidências de sua influência. Conhece-se a existência de correlação entre exposição pré-natal ao tabaco (durante ou depois da gravidez) e ao álcool e baixo peso ao nascer com o TDAH (Barkley \& Murphy, 2008; DuPaul \& Stoner, 2007). 
No Brasil, publicações acerca de uma visão Gestáltica para o TDAH têm, aos poucos, surgido (Antony \& Ribeiro, 2008; Antony \& Ribeiro, 2004, 2005; Guisso \& Fabro, 2016). Antony e Ribeiro, no conjunto de suas publicações, fruto de pesquisa sobre o tema, consideram que a criança com diagnóstico de TDAH tem pouca capacidade de interiorizar sentimentos e utilizar o pensamento reflexivo, o que resulta na impulsividade observada em seu comportamento (Antony \& Ribeiro, 2005). Pode-se compreender essa ideia, do ponto de vista do corpo teórico da Gestalt-terapia, como uma dificuldade de efetuar uma retroflexão saudável, compreendida como um movimento de contenção da energia que seria descarregada no meio, com fins de reajuste da emoção, autocrítica, e evitação de rupturas (Schillings, 2014).

A impulsividade, no campo, acarreta desrespeito à fronteira do outro. Observa-se isso, por exemplo, na dificuldade de cumprir regras, de aguardar a vez e de adiar gratificação de desejos (Antony \& Ribeiro, 2005). A hiperatividade, manifestada de forma premente no corpo - no descontrole deste - seria reflexo de uma desorganização psíquica (Antony \& Ribeiro, 2005). No campo, essa sintomatologia repercutiria, na ampla maioria das vezes, em um retorno negativo, visto que o meio dá o sentido de inapropriado ou errado. A criança, assim, cresce recebendo queixas e depreciações sobre seu corpo (Antony \& Ribeiro, 2005).

A consequência quase inevitável de um feedback negativo do campo é a aquisição de introjetos negativos sobre si, de pensamentos e sentimentos de inadequação. Para a Gestalt-terapia, introjeção disfuncional é o mecanismo pelo qual anexamos à personalidade modos de agir, sentir e avaliar sem passar pelo processo de crítica que culminaria em assimilação (Perls, 1977a). Introjeto é o produto desse mecanismo. Assim, o meio contribui para uma significação negativa da criança; não coopera com uma melhora, pelo contrário, (re)produz o diagnóstico, colabora para a formação de um caráter: um sistema rígido de comportamento petrificado e previsível (Perls, 1977b).

Os introjetos negativos inauguram o conflito entre a necessidade de hiperatividade do corpo, com fins de diminuição da tensão psíquica, e o desejo de abafamento dessa necessidade, a fim de ser aceito (Antony \& Ribeiro, 2005). Esse dilema foi denominado por Perls de Top Dog/Under $D_{o g}^{3}$ ou, em português, Dominador/Dominado, um modo de funcionamento neurótico conflituoso entre as exigências de perfeição introjetadas e a impossibilidade de atendê-las (Perls, 1977b). Aqui nota-se o advento de um dilema existencial entre ser o que se é ou buscar um outro "eu” aceitável. A criança torna-se confusa, não sabe ao certo o que fazer e vive à procura de si (Antony \& Ribeiro, 2005).

\footnotetext{
3 Trata-se de um conflito interno entre uma parte dominadora (Top Dog) e outra dominada (Under Dog). A parte dominadora impõe modos de ser, enquanto a parte dominada se justifica, manipula, coloca-se no lugar de oprimida e impotente (Rodrigues, 2011).
}

Além do exposto a respeito da introjeção, Antony e Ribeiro entendem que o funcionamento da criança com TDAH se organiza em torno de três outras interrupções de contato, a saber: a deflexão, a projeção e o egotismo (Antony \& Ribeiro, 2004, 2005, 2008). A deflexão, mecanismo pelo qual promove-se uma "desenergização" a fim de evitar o contato com outra pessoa e a awareness $^{4}$ de determinados sentimentos e emoções fortes (Polster \& Polster, 2001), que ocorreria por meio da ação motora exacerbada e da desatenção, é tida como a interrupção de contato que define o transtorno. Ela acarretaria no não atendimento à necessidade premente $\mathrm{e}$ um não fechamento de gestalten de forma crônica e cíclica (Antony \& Ribeiro, 2004, 2005, 2008). Isso geraria um constante estado de insatisfação (Antony \& Ribeiro, 2008).

A criança teria na projeção, que é um mecanismo pelo qual se deposita nos outros conteúdos psíquicos cujo reconhecimento em si seria perturbador (Polster \& Polster, 2001), uma forma de defesa, por meio da qual se daria o transbordamento no campo dos introjetos tóxicos, anteriormente referidos, por meio da ação hiperativa (Antony \& Ribeiro, 2004, 2005, 2008). Pela ação egotista no meio, haveria uma tentativa de afirmação de si no mundo, forma por meio da qual se sustentaria a personalidade da criança (Antony \& Ribeiro, 2004,2005 , 2008). Esse seria um movimento saudável, na medida que demonstraria uma preocupação com a própria identidade em detrimento do meio. Nas palavras de Perls, Hefferline e Goodman, no egotismo, há "uma preocupação última com nossas próprias fronteiras e nossa própria identidade em lugar de com o que é contatado" (1997, p. 257).

A proflexão, que é uma forma do indivíduo fazer ao outro o que gostaria que o outro fizesse para si (Schillings, 2014), seria um mecanismo de funcionamento secundário no TDAH. Pela proflexão haveria uma tentativa de reparação do meio por sua conduta. Isso seria manifesto pela criança por meio de um comportamento prestativo e afetuoso (Antony \& Ribeiro, 2004, 2005, 2008).

Diante da exposição do entendimento desses autores, cabem alguns alertas a respeito da forma como devem ser compreendidas essas considerações acerca das interrupções de contato. Há um risco de que possam ser vistas - e isso certamente guiaria a prática profissional de uma forma a objetificar o outro - como tipologias. Contudo, a neurose, que é a perspectiva de compreensão do TDAH para os autores citados, é um processo único e, a despeito de algumas interrupções aparecerem majoritariamente, estas não definem o ser, tampouco podem ser usadas de modo a permitir generalizações simplistas, antes mesmo do contato com a pessoa. Além disso, é importante ainda frisar, para não incorrer no erro de

$4 \quad$ Awareness pode ser definida como "o processo de estar em contato vigilante com o evento mais importante do campo indivíduo/ ambiente, com total apoio sensoriomotor, emocional, cognitivo e energético" (Yontef, 1998, p. 215). 
tomar o saudável por doente, o quanto as manifestações do TDAH podem, para muitas crianças, ser um ajustamento saudável em determinado contexto, este sim neurótico, disfuncional, haja vista o que foi exposto anteriormente nesta sessão acerca de fatores da organização familiar, por exemplo.

Antony e Ribeiro ainda apontam para o aspecto relacional da patologia, na medida que é na relação com o outro que o retorno sobre uma inadequação surge (2005). A criança só se vê doente porque o meio lhe diz isso. Guisso e Fabro 2016 acrescentam à compreensão gestáltica a perspectiva de que a criança com TDAH, à despeito da hipercinesia ${ }^{5}$, não estaria aware do corpo e dos sentimentos.

\section{o Conceito de Campo Como Articu- lador de uma Clínica Ampliada em Gestalt-Terapia}

Nos últimos anos, a psicologia no Brasil vem sendo convocada a atuar não apenas nos contextos clínicos tradicionais, nos consultórios particulares, mas também numa gama cada vez maior de serviços. A psicologia, que durante muito tempo levou a alcunha de elitista, voltada apenas para aqueles que poderiam pagar os altos valores de um processo psicoterápico particular, passou a se democratizar a partir do final dos anos 80 (Conselho Federal de Serviço Social [CFESS] \& Conselho Federal de Psicologia [CFP], 2007). Abriram-se as portas para práticas no campo das políticas públicas, sendo foco neste trabalho a atuação da psicologia em um serviço da Política de Assistência Social.

A psicologia requisitada nesse novo campo de trabalho, no entanto, é voltada, primordialmente, a um trabalho com grupos, coletivos, comunidades. Nesse contexto, emergiu a ideia de uma "clínica ampliada", para além do espaço do consultório e do enquadre tradicionais. A clínica ampliada é uma proposta de diálogo entre a psicologia social e a psicologia clínica, com ênfase na dimensão humana comunitária e que se desenvolve, por meio da escuta e da observação, ações com foco nas redes de relações (Campos \& Daltro, 2015).

Entendendo o TDAH como um fenômeno que convoca a pensar práticas da psicologia na assistência social, cabe ressaltar que, se o psicólogo atender somente à demanda de domesticação dos indivíduos por meio da supressão de sintomas, possivelmente se converterá em um agente produtor de opressão. Transformará instituições que, muitas vezes, são locais para acolhimento de pessoas que sofrem violências as mais diversas, em locais produtores de uma "violência velada", não necessariamente ligada a atos físicos, mas aos afetos e a produção de significados (Schillings, 2011).

A Gestalt-terapia tem uma "ferramenta" importante que influenciou e influencia a estruturação de

\footnotetext{
5 Hipercinesia, no exame do estado mental, refere-se a uma atividade motora descrita como agitada (Sadock, Sadock \& Ruiz, 2017).
}

sua teoria e que ajuda a fugir do risco exposto anteriormente, no que tange a demanda social de adaptação dos sujeitos. Esse recurso teórico permite um olhar para além do indivíduo, bem como contribui sobremaneira para uma melhor compreensão e intervenção sobre o TDAH: a Teoria de Campo.

A Teoria de Campo, proposta por Kurt Lewin, permite observar que o comportamento é uma função de características pessoais e ambientais, sendo, portanto, influenciado de forma complexa pelo ambiente, suas regras e funcionamento. Campo é uma totalidade de fatos que são entendidos como mutuamente interdependentes (Ribeiro, 2006). Utilizando-se da topologia e de suas representações gráficas, Lewin entendia o espaço vital de uma pessoa, como algo composto pelo próprio sujeito, suas crenças, necessidades, metas, e pelo ambiente físico e psicológico (Ribeiro, 2011). Fora do espaço vital estaria o âmbito externo, formado por aquilo que não influencia o comportamento. Para ele, uma pessoa é um sistema de energia e seu comportamento é motivado por suas necessidades mais prementes e a relação destas com os obstáculos apresentados no espaço vital. O mundo é um campo em plena ação e o ser humano, um subcampo, uma parte desse campo mais amplo, em íntima e constante troca (Ribeiro, 2011). Tudo pertence a um campo, não existindo, pois, um sujeito isolado no mundo, sem possibilidade de afetá-lo ou por ele ser afetado, visto que organismo e meio são indissociáveis.

Lewin não se limitou a teorizar sobre o comportamento individual. Ele tratou também de constituir um olhar sobre o contexto cultural ao qual estava inserido, dando suas contribuições à psicologia social, o que pode ser importante para os fins deste estudo. Em um artigo seu, intitulado "Algumas Diferenças Sociais e Psicológicas Entre os Estados Unidos e a Alemanha", Lewin traçou um panorama da cultura educacional nesses dois países em diversos ambientes, como o familiar e o escolar (Lewin, 1948a). Ele deixou claro o quanto a cultura autocrática alemã no período estudado foi um campo fértil para o surgimento do nazismo. Não se trata de um determinismo o que ele expõe, mas da possibilidade de pensar a cultura de um povo como um conjunto de componentes de um campo que facilita a emergência de uma forma de pensar e agir hegemônicas. Do mesmo jeito, pode-se pensar de que forma, no contexto de um serviço de assistência social que atende crianças em situação de vulnerabilidade, a "cultura da instituição" é facilitadora ou eliciadora de um modo de ser-no-mundo TDAH.

Campo, como visto, é um conceito dinâmico que expõe uma complexidade existencial, na medida em que tudo está conectado e com certo grau de dependência. É nesse sentido que a teoria de campo, enquanto uma parte do todo que é a Gestalt-terapia, contribui para uma prática de clínica ampliada. A ideia de unidade entre organismo e ambiente 
sustenta teoricamente a possibilidade de uma clínica ampliada na Gestalt-terapia (Brito, 2015).

Depreende-se daí o quanto a Gestalt-terapia pode e deve cada vez mais se inserir no universo das práticas ditas ampliadas, compreendendo as muitas possibilidades de ação que a teoria de campo fornece. O TDAH se apresenta no campo, logo, as intervenções possíveis, no contexto do serviço de assistência social que permitiu essas reflexões, não podem ser unicamente na lógica da clínica individual.

É preciso lançar mão de intervenções sobre o campo - compreendido como o conjunto de fatores que constituem uma organização, seus funcionários, seus voluntários, suas regras, seu espaço físico, seus atravessamentos políticos, suas concepções éticas, morais e educativas, entre tantos outros - e não apenas sobre sujeito, sendo esse o diferencial do enquadre psicoterápico tradicional. Modificações nos componentes do campo podem repercutir na pessoa cujos sintomas são evidenciados (Ribeiro, 2006). Nesse sentido, é possível voltar o olhar para o TDAH de um modo diferente, de forma a não encapsular o sujeito em um discurso psicologizante, mas a vê-lo como parte de um todo, de uma gestalt estabelecida, como figura de um fundo que o sustenta.

A seguir, este estudo tratará de observar como a sintomatologia descrita no indivíduo pode aparecer também no contexto institucional escolhido. É bem verdade que cada espaço de assistência social que trabalha com crianças tem liberdade de organizar-se singularmente contanto que as diretrizes do trabalho sejam cumpridas. As reflexões que seguem, são fruto de uma experiência, em um desses locais e de observações gerais de outras instituições. Não servem como generalização, mas como facilitadores de reflexão para outros profissionais em outros contextos.

\section{TDAH Como Fundo: Interrup- ções de Contato Institucionais e Possí- veis Intervenções}

O DSM-5 aponta a dificuldade de escutar da criança com TDAH como um dos critérios diagnósticos, afirmando como exemplo que ela "parece estar com a cabeça longe, mesmo na ausência de qualquer distração óbvia" (American Psychiatric Association, 2014, p. 59). Significa dizer que há algo em sua percepção ou em seu pensamento que é a verdadeira figura para a criança.

O mesmo manual afirma que a sintomatologia do TDAH pode ser minimizada ou mesmo não ser evidenciada em situações em que fatores do campo estão modificados (American Psychiatric Association, 2014). Violet Oaklander entende que essa redução dos sintomas sob determinadas circunstâncias se dá quando é oferecida uma escuta e atenção diferenciadas (Oaklander, 1980).

Assim, uma característica disfuncional na criança, que pode ser entendida como expressão de alguma necessidade incompreendida pelo meio, tende a desa- parecer momentaneamente por uma ação deste. Quando é dada relevância à verdadeira figura de interesse, o sintoma minimiza. Entretanto, o campo tende a impor figuras de atenção e despreza as da criança. Entende-se como ação prática embasada no argumento acima, disponibilizar à criança maior supervisão, possibilitando que fique mais perto do educador, conforme proposto por Barkley e Murphy (2008). Desta forma, o educador pode oferecer atenção conforme a necessidade da criança com TDAH.

Contudo, é possível encontrarmos instituições que, por diversas razoes, entre elas o próprio adoecimento dos funcionários, apresente um funcionamento mais rígido, com uma série de regras predeterminadas. Nesses locais, muitas vezes, não há espaço para diálogo e construção conjunta das regras que vão reger o contato interpessoal, dando os limites adequados para uma sadia interação. Há pouco ou nenhum espaço de coparticipação. O fazer torna-se excessivamente metódico e estruturado, à exemplo de uma linha de produção. Aqueles que não se enquadram nesse funcionamento - como as crianças com diagnóstico de TDAH - não têm suas necessidades ouvidas e atendidas e são vistos como problema, por não se enquadrarem na forma cristalizada de funcionamento institucional. Aquilo que a instituição não vê em si, vê na criança, em um funcionamento que pode ser nomeado como projetivo. Cabe ressaltar que a instituição é uma abstração, o que existe é uma gestalt formada por todas as pessoas que a compõe; assim é possível entender a possibilidade de haver uma instituição em disfunção (Ginger \& Ginger, 1995).

É importante destacar aqui que este estudo não se filia à tese de que limites são prejudiciais e de que a criança, aprioristicamente, sabe sempre o que é melhor para si. Pelo contrário, concorda com Aguiar quando esta salienta a necessidade que a criança tem de limites e o quanto pode ser ameaçador a responsabilidade de sempre escolher (Aguiar, 2005). Esse apontamento, no entanto, não invalida as observações a respeito da falta de diálogo, construção de regras coletivamente e escuta das necessidades em alguns ambientes institucionais da assistência social, nos quais a inserção profissional possibilitou essas reflexões. É preciso compreender como se dá a constituição do espaço vital em cada local e o quanto essa constituição reforça ou contribui para as disfuncionalidades naqueles que a frequentam.

Por detrás do comportamento projetivo institucional referido anteriormente, pode-se inferir também uma variada gama de introjetos. Para chegar a esses introjetos, este trabalho lançará mão de alguns exemplos observados na prática de algumas instituições que servirão como facilitadores dessa discussão.

Observou-se que, para realizar um deslocamento de um lugar para outro, o ordenamento em filas era prática comum. As filas eram estabelecidas por critério de altura e de sexo, nunca de afinidade. Solicitava-se silêncio para os deslocamentos. As 
justificativas eram variadas: a inviabilidade de ir de um ponto a outro sem que esse trânsito se transformasse em balbúrdia, a necessidade de mostrar para as crianças a importância da organização e do comportamento solícito à autoridade do educador, o comodismo e o fato dessa ser uma forma lógica de ordenamento que pode dirimir conflitos.

O silêncio ainda era requisitado, por vezes, nos momentos de realização de atividades e de alimentação. Cantar, dançar, rir alto, também representavam um atentado às regras institucionais. Brincar ao ar livre era, por vezes, "criminalizado": não era permitido subir em árvores ou correr "demasiadamente”. Os horários precisavam ser rigidamente cumpridos e tudo que impedia esse intento era visto como prejudicial, devendo ser interrompido ou punido, já que não se percebia eventuais conflitos como oportunidades férteis de trabalho. Apenas o que foi planejado era visto como intervenção útil.

Alguns dos exemplos citados evidenciam três introjetos, os quais dão sustentação ao agir de algumas organizações: o silêncio, a obediência e a ordem enquanto valores fundamentais. É evidente que esses três introjetos são de fato importantes em diferentes contextos e não se objetiva aqui propor um extremo oposto anárquico. Há questionamentos, não obstante, que precisam ser feitos para que se saiba se esses introjetos são ou não realmente tão válidos quando cristalizados, o que essa rigidez impede e o que poderia ser um valioso aprendizado e que está sendo perdido. À luz das ideias de Lewin (1948b), é possível sustentar a afirmação de que essa rigidez não contribui para a construção de uma sociedade em que os cidadãos são educados para o protagonismo, tão almejado pelos projetos técnicos dos serviços da área da assistência social.

Para crianças com diagnóstico de TDAH, andar em fila e em silêncio é uma tarefa difícil. No entanto, nos variados setores onde um adulto comum circula, são poucos os lugares em que são solicitados esses comportamentos. Há uma clara discrepância entre o que se pede a uma criança e o que se pede a um adulto e uma desconsideração do que é possível para ela. As motivações para esse tipo de solicitação, contudo, por vezes são questionáveis, oriundas de um senso de incapacidade pessoal de "controlar" tais crianças, mais do que de uma necessidade real de ordem (Oaklander, 1980).

Essas e outras formas de funcionamento institucional, oriundas de introjetos, acarretam, para uma criança com TDAH apenas a reafirmação de um estigma. A criança é cada vez mais tida como anormal por não se adaptar numa lógica imposta. Essa lógica sim, pode ser chamada de neurótica dadas as suas características, na medida em que não se atualiza, espera a reprodução do mesmo, está cristalizada (Perls, 1977a). Apenas um dos lados é foco das intervenções sejam elas de que ordem forem o que, não raras vezes, produz uma "queda de braço", uma manifestação de campo (e não intrapsíquica) de um conflito dominador/dominado, com dois atores distintos: a instituição e a criança.

Diante das ideias expostas, fica evidente o quanto existe mais de um foco de intervenção possível para o Gestalt-terapeuta que desenvolve um fazer clínico ampliado em ambientes institucionais com características semelhantes aos que fundamentaram as reflexões até aqui e que têm usuários com diagnóstico de TDAH. Tanto a criança quanto as demais pessoas que frequentam a instituição e a configuram de determinado modo são os sujeitos aos quais se destinará a atenção.

Do ponto de vista da criança, as intervenções devem percorrer um itinerário que permita o desenvolvimento do autossuporte, pois, como afirmou Perls, "amadurecer é transcender o apoio ambiental para o autoapoio" (Perls, 1977b, p. 49) e a falta desse suporte em si mesmo acarreta sentimentos e comportamentos disfuncionais (Andrade, 2014). A criança com TDAH precisa de auxilio, a fim de que desenvolva a capacidade de estar mais aware de si mesma (Guisso \& Fabro, 2016), tendo em vista que não há autossuporte sem autoconhecimento e autoaceitação (Andrade, 2014), oferecidos pela ampliação da awareness do indivíduo.

Para favorecer o desenvolvimento da awareness, Oaklander sugere duas possibilidades: oportunizar contato sensório motor, com ação calmante e tranquilizadora, ou acompanhar o rápido mover da atenção, ajudando a criança a perceber o que faz e como faz, experienciando isso de uma forma mais plena (Oaklander, 1980). A primeira alternativa parece ser administrável no contexto institucional em questão. A autora sugere o uso de argila, areia, água, pintura com os dedos. O contato também se dá com as outras pessoas que compõe o campo. Tocar e olhar nos olhos ao comunicar uma instrução são sugestões de recursos facilitadores da comunicação com essas crianças (Barkley \& Murphy, 2008) além de serem outra forma de promover contato sensório motor com o campo. Tais propostas são interessantes, mas são recursos focados no indivíduo.

Em relação a segunda alternativa, Oaklander fala de sua experiência no âmbito escolar, citando a possibilidade de levar em conta aquilo que é foco de atenção da criança em um dado momento e não necessariamente apenas a tarefa. Assim, permite-se que a criança fique um tempo com o que lhe interessa em um dado instante, que observe, sinta e fale algo daquilo, de modo que possa experienciar mais plenamente situações e objetos. Deve-se evitar o julgamento e auxiliar a criança a perceber o que faz e como faz (Oaklander, 1980). Essa proposta de intervenção é sensível à singularidade da experiência com o tempo da criança com TDAH. Exige um olhar institucional sobre o sujeito que não seja avesso ao modo de ser-no-mundo apresentado por essas crianças e que esteja aberto a atender a neces- 
sidades individuais. Além disso, denota duas atitudes fundamentais que uma instituição precisa ter como diretriz de trabalho de seus profissionais que atuam junto a crianças com TDAH: a confirmação e o acolhimento.

A confirmação tem função significativa para o desenvolvimento da criança e estabelecimento de formas saudáveis de relação (Aguiar, 2005). Por meio dela, a criança poderá adquirir um senso de "eu" mais forte, uma elevação de sua autoestima e uma crença de maior capacidade de lidar com suas necessidades, sem desrespeito às do meio (Aguiar, 2005). É muito comum, como visto, que a maior parte do comportamento de uma criança com TDAH seja desqualificado. Muitas vezes - o que é ainda mais devastador - não são os comportamentos que são apontados como equivocados, mas a criança como um todo é depreciada: a parte é tida como o todo e não componente dele. Assim, suas necessidades não são satisfatoriamente atendidas, por não serem ouvidas, podendo gerar uma profusão de gestalten abertas. Esse processo de repressão, pode estar envolvido no agravamento da sintomatologia.

Confirmar, no entanto, não significa agir permissivamente, mas ouvir e ajudar a criança a expressar seus sentimentos e necessidades de maneira mais adequada (Aguiar, 2005), de forma que o meio não seja violentado, fortalecendo o papel educador daquele que desempenha a ação de cuidar. $\mathrm{Na}$ proposta de Oaklander, confirmar é demonstrado pela postura de acompanhar o rápido ir e vir da atenção sem desqualificar esse movimento da criança, ajudando-a a percebê-lo e a contatar o meio de forma mais satisfatória.

A acolhida, por sua vez, pode ser demonstrada através do afeto e do respeito, não condicionados ao comportamento. Em outras palavras, é preciso deixar claro que afeto e respeito são dados a toda criança pelo fato de serem pessoas, independentemente de eventuais dificuldades que possam apresentar. Esse acolhimento integral da singularidade no coletivo pode ser uma forma de trabalhar os introjetos negativos da criança com TDAH acerca de si.

Quando existe um foco muito intenso sobre a criança e nenhum sobre o campo, é necessário construir espaços onde isso possa ser discutido. É preciso que se volte o olhar sobre o todo. Oaklander dá outros exemplos práticos de como agia com grupos de crianças em algumas circunstâncias, o que pode ilustrar muito bem como quebras de paradigma em relação a um funcionamento fixo da instituição podem ser propostas sem causar problemas ou desorganização e promovendo um ambiente mais adequado para qualquer criança. Ela cita o correr ou o deslocar-se livremente, em detrimento de filas ordenadas em todas as circunstâncias e a possibilidade de conversar durante certas atividades quando isto não constituir um problema e não houver razão para silêncio (Oaklander, 1980).
Outra contribuição relevante de Oaklander e que pode auxiliar no processo de pensar a dinâmica de uma instituição que trabalha com crianças é o ponto em que ela trata da importância das crianças ditas "hiperativas" terem a oportunidade de fazer escolhas. Apesar de, para muitas instituições, fomentar uma real participação na construção das tarefas, regras e funcionamento geral seja muito difícil, a autora crê que oportunizar a essas crianças ocasiões em que possam escolher é uma das principais ações a serem tomadas. Fazer escolhas pressupõe um senso de "eu", um movimento de sintonia entre pensamento, sentimento e ação no meio (Oaklander, 1980). Negociar, ao invés de impor, embora não pelas mesmas razões, é uma sugestão de forma de lidar com tais crianças dada também por outros pesquisadores (Barkley \& Murphy, 2008).

Para a construção de espaços de protagonismo, talvez seja interessante pensar, de acordo com as ideias de Lewin, na promoção de características democráticas. Conforme ele, os ambientes grupais democráticos são formados pelos atributos da liderança, dos responsáveis por esses grupos. Esse tipo de liderança deve ser encorajadora, incentivadora de tomada de decisões pelo coletivo, além de facilitadora de um ambiente de liberdade para realização de tarefas e divisão de responsabilidades (Lewin, 1948b).

Richard Louv (2016) atenta ainda para um outro fato que se faz onipresente nos mais variados espaços que qualquer criança circula: a diminuição da possibilidade de contato com a natureza. O autor sustenta que o TDAH é um problema que está menos na criança e mais em um ambiente cada vez mais artificial, o que é coerente com a ideia do TDAH visto da perspectiva de campo. O autor refere as consequências da falta de contato com o mundo natural, bem como da falta de espaços de brincadeira ao ar livre e não estruturadas para as crianças em geral. Entende que uma retomada dessas oportunidades gera melhoras significativas nas crianças com diagnóstico de TDAH, podendo significar uma "terceira via” de atendimento, ao lado da psicoterapia e da farmacoterapia (Louv, 2016). Diante dessas contribuições, pode ser uma via de intervenção tornar a instituição um meio mais "nutritivo", promovendo às crianças um contato com árvores, terra, água, animais, pelas formas que forem viáveis. Essa afirmação toma força diante de estudos sobre ecopsicopatologia, conceito que faz referência à profunda relação entre o humano e a natureza e as consequências à saúde de um distanciamento entre ambos (Carvalho, 2013).

Ainda é importante citar o quanto se faz necessário o chamado "cuidado do cuidador". Aquelas pessoas que ficam em contato direto com dezenas de crianças e adolescentes por dia, que têm a tarefa de planejar e desenvolver um projeto atrativo e educativo. Essas pessoas por vezes são convocadas a lidar com situações para além de suas condições psicoló- 
gicas e carecem também da escuta e do amparo adequados para poderem reproduzi-los ao público que atendem. A solução para uma instituição adoecida passa pelo investimento na saúde de sua equipe.

\section{Em busca de fechamento}

Este trabalho pretendeu trazer a atual compreensão gestáltica do TDAH, conforme consta nas publicações realizadas até o momento, e discorrer sobre a possibilidade de uma prática na lógica da clínica ampliada. Teve como plano de fundo para pensar tais práticas, o contexto da assistência social, mais especificamente de um SCFV.

O TDAH é uma realidade e diz muito do arranjo social vigente. Há um modo de vida, um fundo, que sustenta a possibilidade da emergência dessa figura na atualidade. Muitas crianças sofrem com o conjunto de sinais e sintomas que definem o transtorno, frequentemente tendo dificuldades de relacionamento e aprendizagem. Por isso, há muito ainda a ser dito antes de que esse assunto por se dar por "fechado". A clínica ampliada na perspectiva gestáltica parece ser uma possibilidade de prática profissional bastante potente para o trabalho em espaços comunitários.

Muito há que se compartilhar no meio científico sobre as possibilidades de intervenção. Os pontos expostos a respeito dessas possibilidades neste trabalho são apenas diretrizes, servem como ilustração, não como roteiro fixo, devendo ser experienciadas e avaliadas em cada contexto. O objetivo último deve ser construir um ambiente restaurador para qualquer criança que dele necessite.

\section{Referências}

Aguiar, L. (2005). Gestalt-terapia com crianças: teoria e prática. Campinas: Livro Pleno.

American Psychiatric Association. (2008). Manual diagnóstico e estatísticos dos transtornos mentais (4a ed. rev.). Porto Alegre: Artmed.

American Psychiatric Association. (2014). Manual diagnóstico e estatísticos dos transtornos mentais (5a ed.). Porto Alegre: Artmed.

Andrade, C. C. (2014). Autossuporte e heterossuporte. In Lilian Meyer Frazão \& K. O. Fukumitsu (Eds.), Gestalt-terapia: Conceitos Fundamentais (pp. 147-162). São Paulo: Summus. Retrieved from http://pepsic.bvsalud.org/scielo.php?script=sci_arttext\&pi$\mathrm{d}=\mathrm{S} 1808-42812009000100006 \& \operatorname{lng}=\mathrm{pt} \& \mathrm{nrm}=\mathrm{i}$ so\&tlng $=\mathrm{pt}$

Antony, S. M. da R. (2009). Os ajustamentos criativos da criança em sofrimento: uma compreensão da gestalt-terapia sobre as principais psicopatologias da infância. Estudos e Pesquisas em Psicologia, 9(2), 356-375. Retrieved from http://pepsic. bvsalud.org/scielo.php?script =sci_arttext\&pi$\mathrm{d}=\mathrm{S} 1808-42812009000200007$
Antony, S. M. da R., \& Ribeiro, J. P. (2004). A criança hiperativa: uma visão da abordagem gestáltica. Psicologia: Teoria e Pesquisa, 20(2), 127-134. Retrieved from http:/www.scielo.br/pdf/\%0D/ptp/ v20n2/a05v20n2.pdf

Antony, S. M. da R., \& Ribeiro, J. P. (2005). Hiperatividade: doença ou essência um enfoque da gestalt-terapia. Psicologia, Ciência e Profissão, 25(252), 186-197. Retrieved from http://www.scielo.br/ pdf/pcp/v25n2/v25n2a03.pdf

Antony, S. M. da R., \& Ribeiro, J. P. (2008). Compreendendo a hiperatividade: uma visão da gestalt-terapia. Comun. Ciênc. Saúde, 19(3), 215-224. Retrieved from http://pesquisa.bvsalud.org/portal/ resource/pt/lil-504983

Barkley, R. A., \& Murphy, K. R. (2008). Transtorno de déficit de atenção/hiperatividade: exercícios clínicos (3rd ed.). Porto Alegre: Artmed.

Brito, M. A. Q. (2015). Gestalt-terapia na clínica ampliada. In K. O. Frazão, L.M. e Fukumitsu (Ed.), Gestalt-terapia: a clínica, a relação psicoterapêutica e o manejo em gestalt-terapia (pp. 163-179). São Paulo: Summus.

Caliman, L. V. (2010). Notas sobre a história oficial do transtorno do déficit de atenção/hiperatividade TDAH. Psicologia, Ciência e Profissão, 30(1), 45-61. Retrieved from http://www.scielo.br/pdf/ pcp/v30n1/v30n1a05.pdf

Campos, A. F., \& Daltro, M. (2015). A clínica ampliada no enfoque da gestalt-terapia. Revista Psicologia, Diversidade e Saúde, 4(1), 59-68. Retrieved from https://www5.bahiana.edu.br/index.php/psicologia/article/view/743/524

Secretaria Especial do Desenvolvimento Social. (2015). Convivência e Fortalecimento de Vínculos. Retrieved from http://mds.gov.br/assistencia-social-suas/servicos-e-programas/servicos-de-convivencia-e-fortalecimento-de-vinculos

Ministério do Desenvolvimento Social e Combate à Fome. (2016). Perguntas frequentes: serviço de convivência e fortalecimento de vínculos (SCFV). Retrieved from http://www.mds.gov. br/webarquivos/publicacao/assistencia_social/ perguntas_e_respostas/PerguntasFrequentesSCFV_03022016.pdf

Oaklander, V. (1980). Descobrindo crianças: a abordagem gestáltica com crianças e adolescentes (5th ed.). São Paulo: Summus.

Organização Mundial da Saúde. (2011). Classificação de transtornos mentais e de comportamento da CID-10: descrições clínicas e diretrizes diagnósticas. Porto Alegre: Artmed. 
Pereira, C. de S. C. (2009). Conversas e controvérsias: uma análise da constituição do TDAH no cenário científico nacional e educacional brasileiro. Dissertação de mestrado. Fundação Oswaldo Cruz. Retrieved from https://www.arca.fiocruz.br/handle/icict/4001

Perls, F. S. (1977a). A abordagem gestáltica e testemunha ocular da terapia. Rio de Janeiro: Zahar.

Perls, F. S. (1977b). Gestalt-terapia explicada (11th ed.). São Paulo: Summus.

Perls, F. S., Hefferline, R., \& Goodman, P. (1997). Gestalt-terapia (3rd ed.). São Paulo: Summus.

Polster, E., \& Polster, M. (2001). Gestalt-terapia integrada. São Paulo: Summus.

Rodrigues, H. E. (2011). Introdução à Gestalt-Terapia (8a ed.). Petrópolis, RJ: Vozes.

Ribeiro, J. P. (2006). Vade-mécum de gestalt-terapia: conceitos básicos (2nd ed.). São Paulo: Summus.

Ribeiro, J. P. (2011). O conceito de mundo e de pessoa em gestalt-terapia: revisitando o caminho. São Paulo: Summus.

Ribeiro, J. P. (2012). Gestalt-terapia: refazendo um caminho (8th ed.). São Paulo: Summus.

Sadock, B. J., Sadock, V. A. \& Ruiz, P. (2017). Compêndio de Psiquiatria: Ciência do comportamento e psiquiatria clínica $\left(11^{\mathrm{a}}\right.$ Ed). Porto Alegre, Artmed.

Schwartzman, J. S. (2000). Distúrbios de atenção. In P. B. Sukiennik (Ed.), O aluno problema: transtornos emocionais de crianças e adolescentes (2nd ed., pp. 241-260). Porto Alegre: Mercado aberto.

Schillings, A. (2011). A violência no contexto intrafamiliar e social: um olhar da gestalt-terapia às vivências opressivas. Sampa GT, 6, 45-51.

Schillings, A. (2014). Concepção de neurose em gestalt-terapia. In L.M. Frazão \& K. O. Fukumitsu (Eds.), Gestalt-terapia: conceitos fundamentais (pp. 193-215). São Paulo: Summus.

Thiengo, D. L., Cavalcante, M. T., \& Lovisi, G. M. (2014). Prevalência de transtornos mentais entre crianças e adolescentes e fatores associados: uma revisão sistemática. Jornal Brasileiro de Psiquiatria, 63(4), 360-372. Retrieved from https:// doi.org/10.1590/0047-2085000000046

Yontef, G. M. (1998). Processo, Diálogo e Awareness: Ensaios Sobre Gestalt-terapia (2a ed.). São Paulo: Summus.
Luiz Gustavo Santos Tessaro (orcid.org/0000-00024673-7521) é Mestre em Psicologia pela Universidade do Vale do Rio dos Sinos, Especialista em Psicologia Clínica pelo Conselho Federal de Psicologia, Gestaltterapeuta pela Comunidade Gestáltica - Clínica e Escola de Psicoterapia e Graduado em Psicologia pelo Centro Universitário Metodista IPA. Email: tessaro.luiz@gmail.com

Ana Maria Veiga Lima (orcid.org/0000-0003-42155716) é Psicóloga graduada pela Universidade Federal de Santa Catarina. Especialista em Psicologia Clínica pelo Conselho Federal de Psicologia e Gestalt-terapeuta pelo Comunidade Gestáltica Clínica e Escola de Psicoterapia, Florianópolis/SC. Email: anaveigalima@gmail.com

Recebido em 27.05.2019

Primeira Decisão Editorial em 12.12.2019

Aceito em 15.01.2020 